\title{
AdAM SMITH POMYLIE SIĘ. To NIE EgOISTYCZNE JEDNOSTKI, LECZ SILNE WSPÓLNOTY POWODUJĄ SZYBSZY ROZWÓJ EKONOMICZNY
}

\author{
Mariusz Maziarz, mariusz.mm@gmail.com \\ Uniwersytet Ekonomiczny we Wrocławiu \\ Komandorska 118/120 Wrocław
}

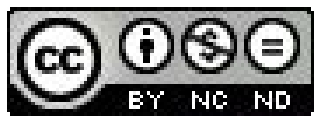

\begin{abstract}
STRESZCZENIE
Zgodnie z dwiema najpopularniejszymi teoriami filozoficznymi poznanie relacji przyczynowej można sprowadzić do (1) zbadania mechanizmów zachodzących pomiędzy zmiennymi (jak mówią zwolennicy realizmu przyczynowego) lub (2) analizy korelacji zachodzącej pomiędzy zmiennymi (za czym opowiadają się filozofowie kontynuujący tradycję Hume'a). W badaniach zastosowano obie metody w celu odpowiedzi na pytanie, czy istnieje relacja przyczyna - skutek pomiędzy wymiarem kultury indywidualizm-wspólnotowość oraz tempem rozwoju ekonomicznego. Przeprowadzona analiza wykazała, że zorientowanie społeczeństwa na wspólnoty powoduje szybszy wzrost gospodarczy.

Słowa kluczowe: wspólnotowość, przyczynowość w ekonomii, determinanty wzrostu, indywidualizm/wspólnotowość
\end{abstract}

Adam Smith Was Wrong. Not Selfish Individuals But Strong Communities Are a Cause of Economic Development

\section{Abstract}

According to the two most popular philosophical theories of causality, there are two ways of recognizing such relations: (1) by understanding mechanisms and processes between variables (in pursuance of causal realism) or (2) by correlation analysis (because, as Hume wrote, it is impossible to cognize the causal relationship itself). I applied these two methods to answer the question if there is cause-effect relationship between one of the cultural dimensions, namely individualism-collectivism and the rate of economic growth. The study carried out on a group of EU countries shows that more collectivistic countries develop faster.

Key words: collectivism, causality in economics, determinants of growth, individualism/collectivism.

Początków współczesnej ekonomii upatruje się w przełomowym dziele szkockiego filozofa O bogactwie narodów. Adam Smith ${ }^{1}$ szukał przyczyn dobrobytu ogółu, czyli tytułowego bogactwa narodów, w działaniach jednostek kierowanych wyłącznie egoistycznym interesem. Zgodnie z poglądem, który stanowił twardy rdzeń ekonomii przez dwa stulecia, maksymalizacja zysku przez przedsiębiorcę, dzięki działaniu niewidzialnej ręki rynku, prowadzi do optymalnych decyzji określających: ile, czego i jak produkować.

Paradygmat racjonalności i efektywności rynków utrzymał się w ekonomii głównego nurtu pomimo występujących w literaturze przedmiotu głosów o wpływie na tempo wzrostu gospodarczego czynników kulturowych (np. głos Maxa Webera ${ }^{2}$ ) oraz problemów z koordynacja, czego przykładem może być sformułowany przez Merilla Flooda i Axela Dreshera w połowie XX wieku tzw. dylemat więźnia. Pomimo wyników badań wskazujących na istotę czynników kulturowych, ludzkich oraz występowanie nieefektywności rynkowych w rzeczywistej gospodarce, Robert Solow ${ }^{3}$ sformułował neoklasyczny model wzrostu, w którym wielkość produkcji gospodarki zależała wyłącznie od poziomu kapitału (K), technologii i jakości oraz liczby pracowników (L):

$$
Q=f(K, L)
$$

1 Smith A., 2007, An Inquiry into the Nature and Causes of the Wealth of nations, Soares S. M. (red.), MetaLibri, http://metalibri.wikidot.com/ title:an-inquiry-into-the-nature-and-causes-of-the-wealth-of; 11.04.2014.

2 M. Weber, The objectivity of the Sociological and Social-Political Knowledge, [w:] 2004, The Essential Weber: A Reader, Psychology Press, 1904.

3 R. Solow, A contribution to the Theory of Economic Growth, "Quarterly Journal of Economics”, 1956, tom 70, nr 1; s. 65-94. 


\section{WPEYW SPOEECZEŃSTWA NA GOSPODARKE}

Wpływ miękkich czynników na rozwój ekonomiczny zaczął być dostrzegany dopiero kilkadziesiąt lat temu. Jednakże, pomimo publikacji Culture's consequences Geerta Hofstede, wciąż pokutował pogląd, iż istnieje związek pomiędzy szybkim tempem wzrostu gospodarczego i indywidualistycznymi zachowaniami jednostek, które kierują się wyłącznie maksymalizacją zysku. Richard Peterson ${ }^{5}$ uznał, że nasilenie wartości przeciwnych do indywidualizmu, tj. wspólnotowości, negatywnie wpłynie na rozwój ekonomiczny. David McClelland ${ }^{6}$ i G. Hofstede ${ }^{7}$ uzasadniali powyższy wniosek odwróceniem ludzi od orientacji na osiągnięcia związanej z potrzebą przynależności.

Wpływ poziomu indywidualizmu/wspólnotowości społeczeństwa na gospodarkę zaczęto oceniać pozytywnie dopiero w latach dziewięćdziesiątych ubiegłego wieku. Dla przykładu, Kellner ${ }^{8}$ pisał w „Sunday Time”s, że niskie tempo wzrostu brytyjskiej gospodarki może być spowodowane przez wysoki poziom indywidualizmu pracowników - przywolał przy tym korelację tempa wzrostu PKB w 18 najbardziej uprzemysłowionych krajach świata i poziomu indywiduali$\mathrm{zmu}(\mathrm{r}=0,67)$ mierzonego zgodnie $\mathrm{z}$ miarą opracowaną przez Hofstede (1980) na podstawie analizy danych ankietowych z Value Survey Module. W analizowanym wymiarze kultury przeciwieństwem indywidualizmu jest wspólnotowość (ang.: individualism/collectivism), rozumiana jako przeświadczenie, iż „wspólne i solidarne działania przynoszą nie gorsze rezultaty niż nieograniczona konkurencja na rynku odizolowanych od kontekstu społecznego i racjonalnych jednostek"

W ostatnich latach opublikowano szereg badań wskazujących na możliwe istnienie związku pomiędzy orientacją społeczeństw na wspólnoty a tempem rozwoju ekonomicznego. Robert Putnam ${ }^{10}$ wskazał na większą efektywność instytucji w społeczeństwach zorientowanych wspólnotowo. Nina Rosenbusch,-J. Brickmann, i A. Bausch ${ }^{11}$ oraz Mark Taylor i Sean Wilson ${ }^{12}$ zaobserwowali związek analizowanego w pracy wymiaru kultury z poziomem innowacyjności. Louise Parkes i inni ${ }^{13}$ zaobserwowali zaś zwiększone zaangażowanie pracowników w kulturach zorientowanych wspólnotowo.

W związku z istniejącym w literaturze przedmiotu zróżnicowaniem opinii w dalszej części pracy podejmuje się próbę odpowiedzi na pytanie, czy pomiędzy poziomem orientacji na wspólnoty a tempem rozwoju ekonomicznego istnieje zależność przyczynowa. We współczesnym dyskursie filozoficznym istnieją dwie ważne teorie przyczynowości, które mogą mieć zastosowanie w prowadzonych $\mathrm{w}$ artykule rozważaniach.

Mianem realizmu przyczynowego nazywa się pogląd, zgodnie z którym relacja przyczyna - skutek rzeczywiście istnieje w świecie, poza podmiotem poznającym. Taki sposób istnienia jest dobrze rozumiany przez jednego z bohaterów bajki napisanej przez Alana Milne'a ${ }^{14}$ : na pytanie Kubusia Puchatka o biegun północny Krzyś odpowiada: To jest coś, co się odkrywa ${ }^{15}$. Realiści (przyczynowi) twierdza, że relacja przyczynowa pomiędzy Xi Y istnieje wtedy i tylko wtedy, gdy istnieją mechanizmy przyczynowe łączące wspomniane X i Y. W jaki sposób należy rozumieć pojęcie mechanizmu przyczynowego w naukach społecznych? Daniel Little definiuje to pojęcie jako „sekwencja zdarzeń, warunków i procesów prowadzących z przyczyny do skutku"16. Realizm przyczynowy postuluje, by empiryczne dowody istnienia zależności przyczynowej rozszerzone były o analizę mechanizmu postulowanego związku pomiędzy przyczyną i skutkiem ${ }^{17}$.

\footnotetext{
4 G. Hofstede, Culture's consequences, Beverly Hills, 1980.

5 R. Peterson, Entrepreneurship and organization, [w:] Nystorm P. i Starbuck W., (red.) Handbook of Organizational Design, tom 1, 1980, s. 69-70.

6 D. McClelland, The Achieving Society, New York, 1976.

7 G. Hofstede, Empirical models of cultural differences, [w:] Bleichrodt N., Drenth P. (red.), Contemporary issues in cross-cultural psychology, Lisse, 1991, s. 76.

8 P. Kellner, 1994, Sunday Times, 20. lutego, sekcja 4, s. 4.

9 T. Dołęgowski, Rozwój gospodarczy a wartości wspólnotowe. Między konkurencyjnościa a solidarnościa [w:] T. Dołęgowski i in., Rozwój gospodarczy a wartości wspólnotowe, Warszawa 2012, s. 12.

10 R. Putnam, Making Democracy Work: Civic Traditions in Modern Italy, Princeton, 1993.

11 N. Rosenbusch, J. Brickmann, A. Bausch, Is innovation always beneficial? A meta -analysis of the relationship between innovation and SMEs, „Journal of Business Venturing", 2011 tom 26, str. 441-457.

12 M. Taylor, S. Wilson, Does culture still matter?: The effects of individualism on national innovation rates, "JJournal of Business Venturing", 2012, tom 27, s. 234-247.

13 L. Parkes i in., Person-organization fit across cultures: an empirical investigation of individualism and collectivism, „Applied Psychology: And International Review",2001, tom 50, nr 1, s. 81-108.

14 M. Maziarz, Spór o obiektywne istnienie obiektów teorii ekonomicznych. Argument na rzecz esencjalizmu, "Przegląd Prawniczy, Ekonomiczny i Społeczny", 2013, nr 4 .

15 A. Milne, Kubuś Puchatek, Nasza Księgarnia, 1988, s. 111.

16 D. Little, Varieties Of Social Explanation: An Introduction To The Philosophy Of Social Science, 1991, s. 15.

17 M. Lewis-Beck (red.), The SAGE Encyclopedia of Social Science Research Methods, 2003, s. 100.
} 
Drugim z opozycyjnych sposobów rozumienia relacji przyczyna - skutek jest utożsamienie relacji przyczynowej z regularnością. Zwolennicy poglądów Davida Huméa, stojąc w opozycji do poglądu opisanego powyżej, uważaja, że rzeczywistość nie ma charakteru przyczynowego. Świat zewnętrzny po prostu , jest"18. W związku z tym relacje przyczynowe są przez nich utożsamiane z regularnościami empirycznymi, czyli korelacja, modelem lub grafem przyczynowym.

W dalszej części artykułu wykorzystano omówione powyżej rozumienia relacji przyczynowej do przeprowadzenia analizy związku pomiędzy poziomem wspólnotowości w społeczeństwie a tempem rozwoju gospodarczego. Część 2 zawiera analizę rozumienia pojęć wspólnotowości i indywidualizmu oraz opis ich przejawów ekonomicznych i sposobów mierzenia. Część 3 obejmuje analizę mechanizmów, za pomocą których wyższy poziom orientacji społeczeństwa na wspólnoty wpływa na tempo rozwoju gospodarczego. Rozdział 4 zawiera analizę ekonometryczną badanej relacji. W ostatniej części przedstawiono wnioski z przeprowadzonego badania, możliwość ich zastosowania w polityce gospodarczej oraz omówiono kierunki dalszych badań.

\section{WSPÓLNOTOWOŚć A INDYWIDUALIZM}

Przed przystąieniem do analizy badanego związku przyczynowego należy właściwie zdefiniować pojęcia indywidualizmu i wspólnotowości, odpowiedzieć na pytanie, w jaki sposób można mierzyć ten wymiar kultury oraz zbadać przejawy zorientowania społeczeństwa na wspólnoty oraz na indywiduum w życiu gospodarczym.

Tabela 1. Cechy społeczeństw zorientowanych na wspólnoty

\begin{tabular}{|l|ll|}
\hline Autorzy badania & Wskazywane cechy społeczeństw zorientowanych na wspólnoty \\
\hline Stephen Knack i Philip Keefer ${ }^{19}$ & a) & Świadomość wspólnotowa; \\
& b) & identyfikacja z grupa; \\
& c) & zależność emocjonalna od innych; \\
& d) & solidarność grupowa; \\
& e) & dzielenie sie obowiązkami i przywilejami; \\
& f) & potrzeba stabilności; \\
& g) & relacje przyjaźni, których nie wybierają jednostki (ang.: \\
& h) & predetermined) \\
& i) & partykularyzm. \\
\hline Fang Chen i Stephen West $^{20}$ & $\bullet$ & Jedność z innymi ludźmi; \\
& $\bullet$ & poczucie fundamentalnego połączenia z innymi; \\
& $\bullet$ & orientacja na relacje; \\
& $\bullet$ & zorientowanie interpersonalne. \\
\hline James Tiessen ${ }^{21}$ & {$[1]$} & Wymóg braku konfliktu wewnątrz grup; \\
& {$[2]$} & harmonijna współpraca w grupie; \\
& {$[3]$} & oczekiwanie na pojawienie się konfliktu w kontakcie z osobami \\
& & należącymi do innej grupy. \\
\hline
\end{tabular}

Źródło: opracowanie własne

Psychologowie kultury definiują wspólnotowość, przywołując istotę przynależności jednostki do grupy oraz stawianie celów grupowych ponad własnymi ambicjami: „(...) wspólnotowość uważa grupę (np. rodzinę, klan lub państwo) jako pierwszorzędną jednostkę rzeczywistości i wymaga, by jednostki poświęciły się dla dobra interesów wspólnoty"22.

Wspólnotowość w badaniach prowadzonych przez ekonomistów jest najczęściej stawiana w opozyçi do indywidualizmu. Taka orientacja społeczeństwa wiąże się ze stawianiem przez jednostki na pierwszym miejscu relacji interpersonal-

18 J. Williamson, 2009, Probabilistic Theories, The Oxford Handbook of Causation, Beebee H. i in. (red.), Oxford University Press.

19 S. Knack, Ph. Keefer, Does Social Capital Have an Economic Payoff?, „The Quarterly Journal of Economics”, 1997, tom 112, nr 4, s. 1251-1288.

20 F. Chen, S. West, Measuring individualism and collectivism: The importance of considering differential components, reference groups, and measurement invariance, ,JJournal of Research in Personality", 2008, tom 42, s. 259-294.

$21 \mathrm{~J}$. Tiessen, Individualism, Collectivism and Enterpreneurship: a Framework for International Comparative Research, „Journal of Business Venturing", 1997 , tom 12, s. 367-384.

22 A. Realo i in., Three components of individualism, „European Journal of Personality", 2002, tom 16, s. 163-184. 
nych oraz z poczuciem jedności z innymi ludźmi, co powoduje, że cele wspólnoty są uważane za priorytetowe. Taki stan rzeczy oznacza, że w społeczeństwach wspólnotowych dużą wartość przywiązuje się do solidarności z innymi, zarówno w zakresie obowiązków, jak również przywilejów, por. Tabela 1.

Ponadto, w społeczeństwach komunitarystycznych obserwuje się wyższy poziom zaufania ${ }^{23}$ i silniejsze więzi społeczne ${ }^{24}$, które często wypełniają rolę redystrybucyjna, jaką w gospodarkach wysokorozwiniętych zwykło przypisywać się państwu ${ }^{25}$. Powyższe zjawisko pozwala na zmniejszenie roli państwa w zapewnieniu opieki socjalnejej. Wspólnoty zapewniają także efektywną opiekę nad osobami starszymi, o czym świadczy dodatnia zależność pomiędzy wskaźnikiem IC, mierzącym poziom wspólnotowości, a wielkością wydatków na opiekę nad osobami starszymi, por. Rysunek 1 .

Rysunek 1. Dodatnia korelacja poziomu wspólnotowości i wydatków na opiekę osób starszych

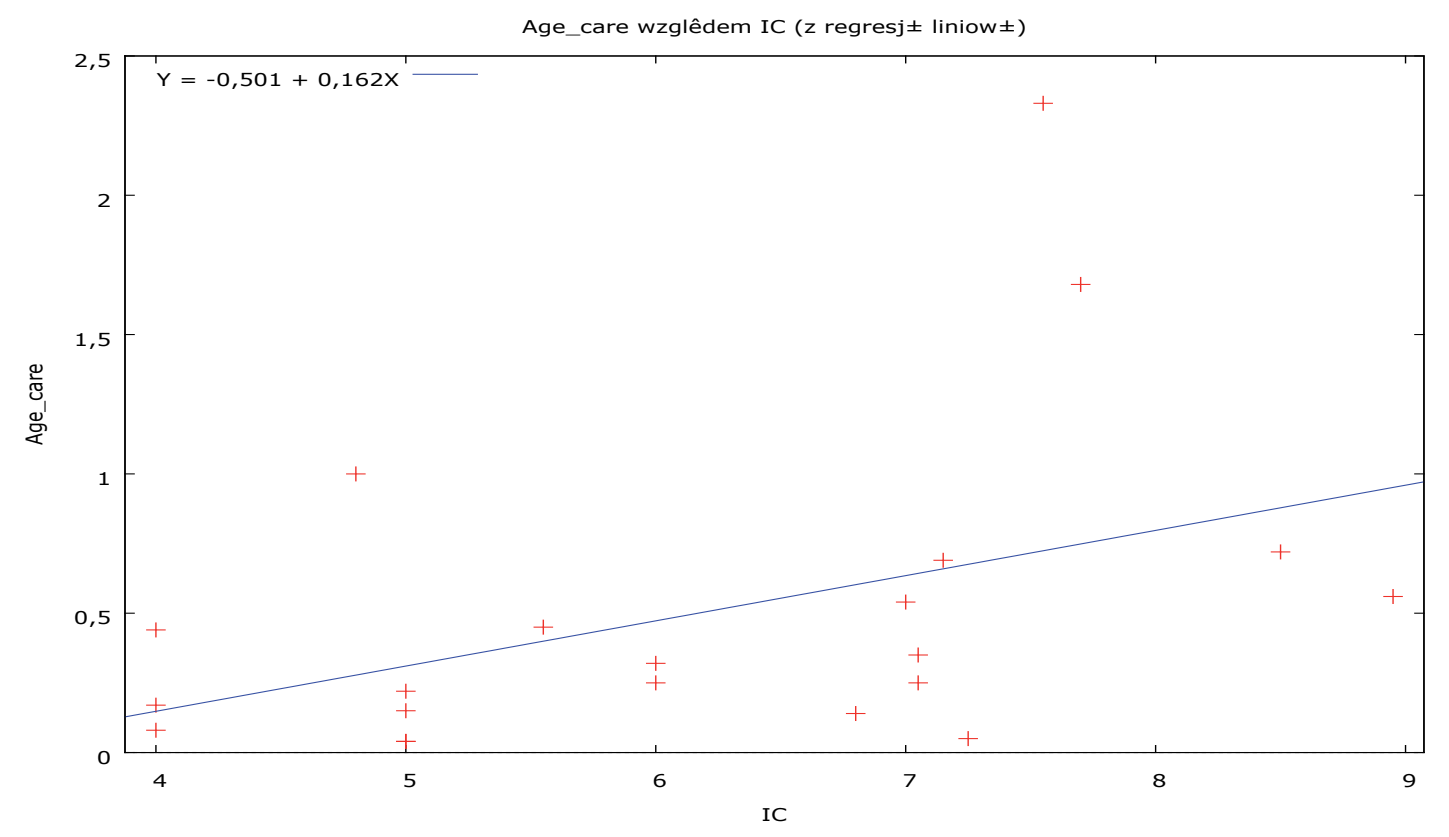

Źródło: opracowanie własne

Indywidualizm jest zwykle traktowany jako przeciwieństwo scharakteryzowanej powyżej orientacji na wspólnoty. Taka orientacja społeczeństwa wiąże się z silną potrzebą konkurowania i wyróżnienia się jednostki, por. Tabela 2. Cechy istotne dla indywidualizmu zostały dobrze podsumowane przez autorów Individualism-Collectivism. A Study of Cross-Cultural Researchers. Jest to: „uczucie lub zachowanie, w którym przewodnią zasadą jest korzyść jednostki”27.

Aby trafnie ocenić istnienie relacji przyczynowej pomiędzy orientacją na wspólnoty a tempem wzrostu gospodarczego, należy wybrać odpowiedni sposób mierzenia analizowanego wymiaru kultury. Od powstania pierwszej pracy na temat indywidualizmu/wspólnotowości podjęto ponad 60 prób opracowania miary określającej orientaçę społeczeństwa. Niestety, jedynie dwie z nich mogą zostać użyte do przeprowadzonej w czwartej części analizy ekonometrycznej, ponieważ tylko wskaźnik IND/ COL opracowany przez G. Hofstede ${ }^{28}$ oraz IC ${ }^{29}$ obejmuje wszystkie lub większość państw należących do Unii Europejskiej.

23 S. Ketkar i in., The impact... dz. cyt.

24 Power i in., The cultural characteristic of individualism/collectivism: A comparative study implications for investment in operations between emerging Asian and industrialized Western cuntries, „JJournal of Operations Management,2010, nr 28, s. 206-222.

25 R. Ball, Individualism, Collectivism, and Economic Development „The Annals of the American Academy of Political and Social Science", 2001, tom 573 , s. $57-84$

26 J.Siewierski, Autonomia jednostki a wspólnota. Analiza Porównazwcza rozwoju gospodarczego na Zachodzie i w Azji Wschodniej [w:] T. Dołegowski i in., Wartości wspólnotowe a rozwó́ gospodarczy, Warszawa 2012.

27 H. Triandis, C. Hui, Individualism-Collectivism. A Study of Cross-Cultural Researchers, ,JJournal of Cross-Cultural Psychology",1986, tom 17, nr 2, s. 225-248.

28 G. Hofstede, Culture's... dz. cyt.

29 E. Diener i in., Similarity of the relations between marital status and subjective well-being across cultures, „JJournal of Cross Cultural Psychology", 2000, tom 31, s. 419-436. 
Tabela 2. Cechy społeczeństw indywidualistycznych

\begin{tabular}{|c|c|}
\hline Autorzy badania & Wskazywane cechy \\
\hline Fang Chen i Stephen West ${ }^{30}$ & $\begin{array}{ll} & \text { Niezależność; } \\
\text { - } & \text { konkurencyjność; } \\
\text { - } & \text { unikatowość jednostek. }\end{array}$ \\
\hline Eva Green i in. ${ }^{31}$ & $\begin{array}{ll}\text { - } & \text { Niezależność; } \\
\text { - } & \text { samodzielność; } \\
\text { - } & \text { unikatowość; } \\
\text { - } & \text { przywiązanie do osiągnięć; } \\
\text { - } & \text { odpowiedzialność za swoje zachowania. }\end{array}$ \\
\hline James Tiessen $^{32}$ & $\begin{array}{ll} & \text { Potrzeba osiągnięć; } \\
\text { - } & \text { ukierunkowanie na siebie; } \\
\text { - } & \text { siła przebicia; } \\
\text { - } & \text { stymulacja. }\end{array}$ \\
\hline
\end{tabular}

Źródło: Opracowanie własne.

Rysunek 2. Wykres rozrzutu pomiędzy miarami wspólnotowości/indywidualizmu: IC i IND/COL

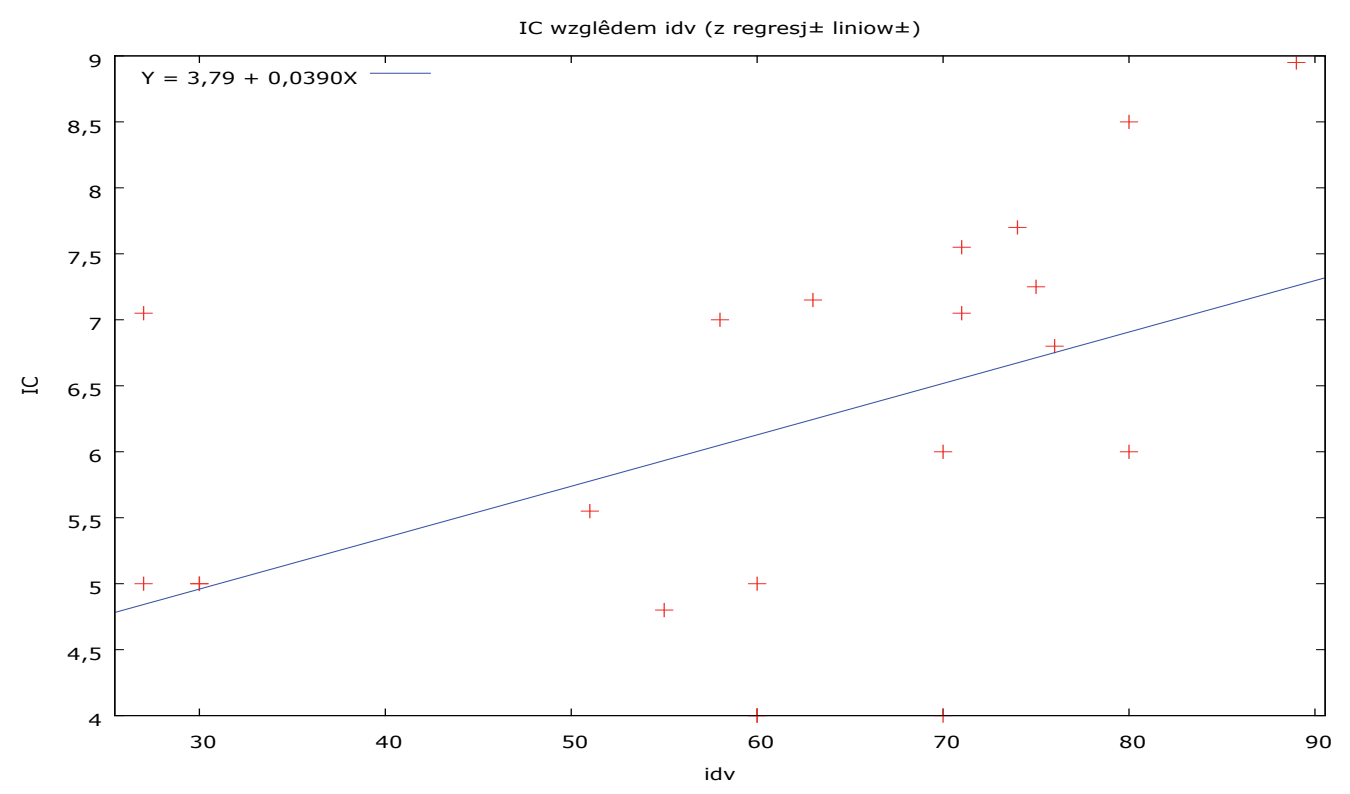

Źródło: opracowanie własne

Obie miary mają za zadanie mierzyć ten sam konstrukt, jednakże wartości wspomnianych wskaźników dla poszczególnych krajów europejskich znacznie się różnią ( $\mathrm{r}=0,485, \mathrm{p}=0,026)$, por. Rysunek 2 . Zróżnicowanie podkreśla istotność właściwego wyboru. Ze względu na obecną w literaturze przedmiotu krytykę miary indywidualizmu opracowanej przez G. Hofstede zdecydowano się na wykorzystanie wskaźnika IC. Indeks IND/COL jest krytykowany m. in. za ujemną korelację z poziomem zaangażowania społecznego ${ }^{33}$, powiązanie raczej z celami pracy niż wymiarem kultury, który ma za zadanie mierzyc ${ }^{34}$.

Do zmierzenia poziomu orientacji na wspólnoty można również użyć niektórych zmiennych makroekonomicznych. Wyższy poziom wspólnotowości oznacza, że jednostki mogą liczyć na solidarność społeczną i pomoc w trudnych sytuacjach ${ }^{35}$, więc można przypuszczać, że w takich społeczeństwach państwowe wydatki socjalne będą niższe, por. Rysunek3.

30 F. Chen, S. West, Measuring... dz. cyt.

31 E. Green i in., Variation of Individualism and Collectivism within and between 20 Countries: A Typological Analysis, ,JJournal of Cross-Cultural Psychology",2005, tom 36, nr. 3, s. 321-339.

32 J. Tiessen, Individualism... dz. cyt.

33 J. Johnson, T. Lenartowicz, Culture, Freedom and Economic Growth: Do Cultural Values Explain Economic Growth?, „Journal of World Business", 1998, tom 34, nr 4, 1998,s. 332-356.

34 F. Chen, S. West, Measuring... dz. cyt.

35 R. Ball, Individualism, Collectivism... dz. cyt. 
Rysunek 3. Wykres rozrzutu wskaźnika IC i wielkości wydatków na cele społeczne per capita

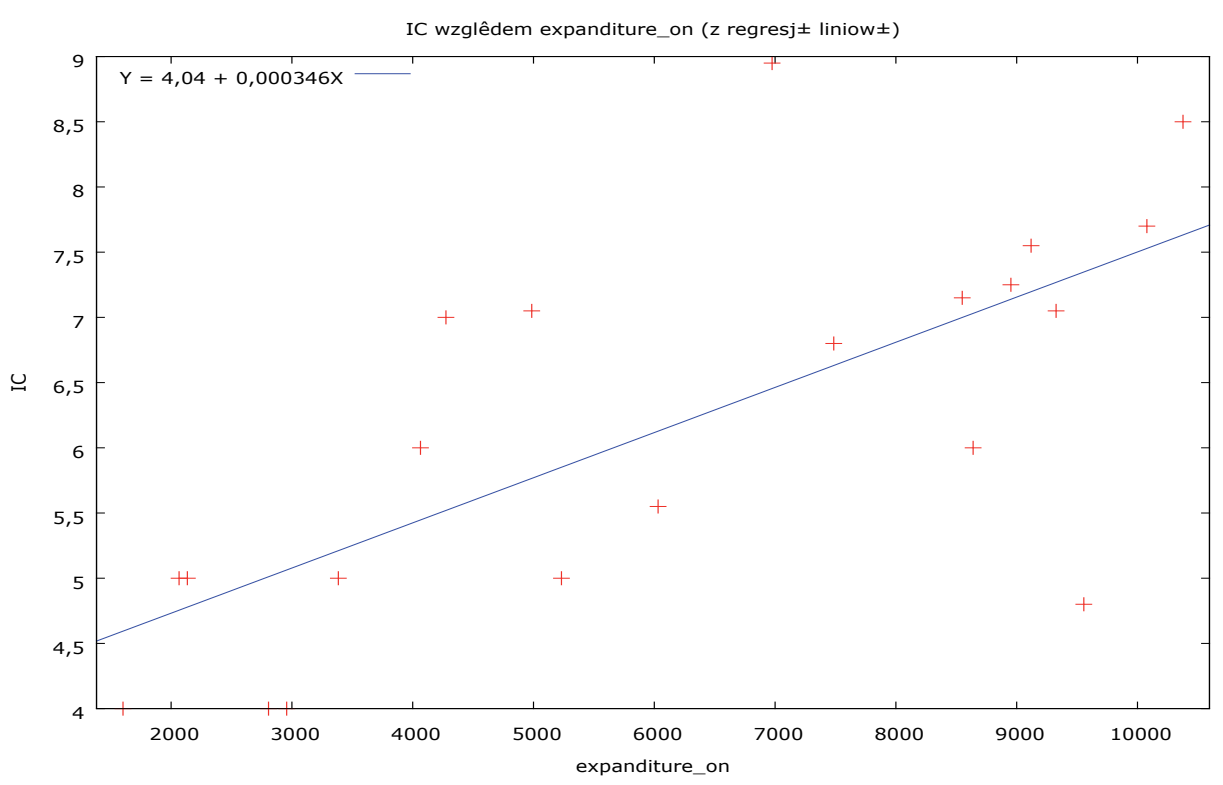

Źródło: opracowanie własne

\section{MECHANIZMY ŁĄCZĄCE ORIENTACJĘ NA INDYWIDUUM LUB WSPÓLNOTY Z TEMPEM ROZWOJU EKONOMICZNEGO}

Celem niniejszego rozdziału będzie przedstawienie grupy mechanizmów (procesów), poprzez które analizowany w pracy kulturowy wymiar społeczeństwa wpływa na wielkość dóbr produkowanych w krajowej gospodarce. Na podstawie przeprowadzonego badania literatury przedmiotu z zakresu socjologii, nauk o zarządzaniu i psychologii na temat możliwych dróg oddziaływania, można wyróżnić cztery mechanizmy wpływu orientacji społeczeństwa na wspólnoty na tempo rozwoju ekonomicznego:

1. Bardziej efektywne relacje pomiędzy podmiotami gospodarczymi.

2. Rzadsze łamanie reguł gry ekonomicznej.

3. Większe bezpieczeństwo jednostek.

4. Pozytywny wpływ na innowacyjność.

Bardziej efektywne relacje pomiędzy podmiotami gospodarczymi. Orientacja społeczeństwa na wspólnoty wyraża się m. in. w poczuciu jedności z innymi ludźmi, ${ }^{36}$ co powoduje, że jednostki utożsamiają się z celami grupy i wkładają $\mathrm{w}$ ich realizację tyle samo wysiłku, ile-włożyłyby w wykonanie własnych, indywidualnych zadań. Do takiego wniosku dochodzą Nagarajan Ramamoorthy i in. ${ }^{37}$, którzy zbadali efektywność i poziom motywacji pracowników z Irlandii i Indii. Zatrudnieni w drugim z nich, ti. kraju uważanym za bardziej wspólnotowy, wykazywali większe zaangażowanie. Naukowcy podsumowali swoje badanie, wskazując, że wyższy poziom wspólnotowości w społeczeństwie koreluje z większym zaangażowaniem i wysiłkami pracowników, ponieważ wymiana między zatrudnionym a przedsiębiorstwem nie jest ograniczona do roli czysto transakcyjnej, co przyczynia się do wyższego poziomu produktywności.

Jednakże zakres analizowanego tu mechanizmu nie ogranicza się wyłącznie do stosunku pracy. Knacki Keefer ${ }^{38}$ wskazuja, że wyższy poziom lojalności w stosunku do innych członków grupy, pozytywnie skorelowany z poziomem wspólnotowości, przyczynia się do rzadszego występowania zachowań kontrproduktywnych wymierzonych w kooperanta. W społeczeństwach wspólnotowych umowy są dotrzymywane częściej, co pozwala zmniejszyć poziom sformalizowania i biurokracji gospodarki. W gospodarkach tworzonych przez społeczeństwa wspólnotowe można, jak twierdzi R. Putnam³ ${ }^{39}$, zaobserwować aktywność banku usług (ang. favour bank), który przypomina ten opisany w powieści The Bonfire of the Vanities.

36 F. Chen, S. West, Measuring... dz. cyt.

37 N. Ramamoorthy i in., Individualism-collectivism orientation and employee attitudes: A comparison of employees from the high-technology sector in India and Ireland, "Journal of International Management", 2007, tom 13, s. 187-203.

38 S. Knack, Ph. Keefer, Does Social Capital Have... dz. cyt.

39 Putnam R., The Prosperous Community: Social Capital and Public Life [w:] K. Blair, R. Murphy, J. Almjeld, (red.), Cross Currents: Cultures, Communities, Technologies, London, 2013, str. 251-252. 
Pomimo głosu Johna Wagnera ${ }^{40}$, że osoby zorientowane wspólnotowo wykazują wyższy poziom zaufania jedynie w kontaktach z członkami tej samej grupy, a jednocześnie charakteryzują się niższym poziomem zaufania niż indywidualiści w stosunku do osób spoza grupy, można stwierdzić, że relacje handlowe w społeczeństwach wspólnotowych charakteryzują się pokładaniem większej ufności w relacii kupiec-sprzedawca, ponieważ, zgodnie z wynikami uzyskanymi przez Sonię Ketkar i in. ${ }^{41}$, większość ankietowanych uczestników wymiany uważa się za członków grupy tworzonej wraz z partnerem handlowym. Dzięki temu relacje biznesowe nie mają w takich kulturach charakteru wyłącznie transakcyjnego. Ponadto sposób przeprowadzania transakcji w społeczeństwach wspólnotowych różni się częstszym wykorzystaniem bezpośredniej komunikacji (ang. face-to-face), co powoduje większe zaangażowanie stron i wypełnienie warunków transakcji oraz zaangażowanie dostawców w proces produkcji. W związku z powyższym, w gospodarkach państw o kulturze wspólnotowej notuje się dłuższe trwanie relacji biznesowych, co przyczynia się do obniżenia kosztów transakcyjnych.

Kontestatorzy bronionej w artykule hipotezy mogliby zapytać, czy efektywne relacje pomiędzy podmiotami ekonomicznymi mogą wpływać na tempo rozwoju ekonomicznego. Odpowiedź, jakiej na podstawie przeglądu literatury udzielił J. Tiessen ${ }^{42}$, jest pozytywna: efektywność wykorzystania zasobów zależy od jakości relacji pomiędzy partnerami, która jest wyższa w społeczeństwach zorientowanych wspólnotowo.

Jednakże wyższy poziom zaufania ma pozytywny wpływ na tempo wzrostu gospodarczego nie tylko poprzez zapewnienie bardziej efektywnych relacji biznesowych. Zgodnie z dedukcją przeprowadzoną przez Paula Zaka i Stephena Knacka ${ }^{43}$ na podstawie założeń teorii równowagi ogólnej, w gospodarkach tworzonych przez społeczeństwa wspólnotowe przeznacza się większą część dochodu na inwestycje.

Rzadsze łamanie reguł gry ekonomicznej. Drugą istotną dla tempa rozwoju ekonomicznego cechą społeczeństw wspólnotowych jest rzadsze występowanie zachowań egoistycznych w takich wspólnotach, wynikające z poczucia więzi z innymi ludźmi. Można domniemywać, że w krajach, w których przeważa orientacja na wspólnoty, w zachowaniach aktorów ekonomicznych będzie obserwować się empatię oraz zgodność z ważnymi dla tego społeczeństwa normami etycznymi ${ }^{44}$.

Ograniczenie zachowań egoistycznych w kulturach wspólnotowych zostało zaobserwowane przez wielu badaczy. Sidney Cobb ${ }^{45}$ oraz Raoul Naroll ${ }^{16}$ wskazują na istnienie związku pomiędzy indywidualizmem i przestępczością: im bardziej indywidualistyczne jest społeczeństwo, tym więcej przestępstw notuje się w przeliczeniu na 1000 mieszkańców. Prawdopodobną przyczyną istnienia takiego związku jest większe uznanie dla norm grupowych w społeczeństwach wspólnotowych ${ }^{47}$. Dzięki przestrzeganiu przez jednostki norm grupowych społeczeństwa mogą dokonywać bardziej efektywnych wyborów w sytuacjach, w których egoistyczne zachowania przyczyniają się do powstania problemu koordynacji, podobnie jak w dylemacie więźnia.

Ponadto większe prawdopodobieństwo, że partner handlowy będzie przestrzegał ustaleń i prawa, wpływa, podobnie jak wyższy poziom zaufania, na obniżenie kosztów transakcyjnych. Lenard Huff i Lane Kelley, po przeprowadzeniu analizy wpływu wspólnotowości na konkurencyjność na przykładzie sześciu państw azjatyckich i dwóch stanów USA, piszą: „,prawdopodobieństwo, że osoba zorientowana wspólnotowo zaangażuje się w nieetyczne zachowanie jest niskie, ponieważ ludzie (w społeczeństwach wspólnotowych) są przywiązani do grupowych wartości i wierzeń oraz dążą do osiągnięcia interesu grupy" ${ }^{48}$.

Większe bezpieczeństwo jednostek. Społeczeństwa wspólnotowe nie tylko narzucają obowiązki związane z przestrzeganiem norm grupowych, lecz również zapewniają poczucie bezpieczeństwa i pomoc, gdyż solidarność jest jedną $\mathrm{z}$ cech takich cywilizacji ${ }^{49}$. Jednym z przejawów powyższych cech w życiu gospodarczym jest pomoc w znalezieniu i utrzymaniu pracy. W społeczeństwach o orientacji wspólnotowej notuje się dłuższy średni czas pracy w jednym przedsiębiorstwie $e^{50}$.

40 J. Wagner, Studies of Individualism-Collectivism: Effects on Cooperation in Groups, "Academy of Management Journal", tom 38, 1995, s. $152-172$.

41 S. Ketkar i in., The impact of... dz. cyt.

42 J. Tiessen, Individualism, Collectivism... dz. cyt.

43 P. Zak, S. Knack, Trust and Growth, „The Economic Journal”, 2001, tom 111, nr 470, s. $295-321$.

44 F. Chen, S. West, Measuring individualism dz. cyt.

45 S. Cobb, Social support as a moderator of life stress, "Psychomatic Medicine", 1976, tom 38, s. 300-314.

46 R. Naroll, The moral order, Beverly Hills 1983.

47 J. Coleman, Social capital... dz. cyt.

48 L. Huff, L. Kelley, Is collectivism a liability? The impact of culture on organizational trust and customer orientation: a seven-nation study, "Journal of Business Research", 2005, tom 58, s. 96-102.

49 S. Knack, Ph. Keefer, Does Social Capital... dz. cyt.

50 L. Gomez-Mejia, T. Wellbourne, Compensation strategies in a global context, „Human Resource Planning”,1991, tom 14, s. 29-41. 
Pomoc innym członkom społeczeństwa nie ogranicza się, oczywiście, wyłącznie do miejsca pracy. Solidarność przejawia się również w formie pomocy materialnej gorzej uposażonym oraz znajdującym się w trudnej sytuacji życiowej członkom społeczeństwa, co może pozytywnie wpływać na tempo rozwoju ekonomicznego, ponieważ koszt tak świadczonej pomocy jest niższy od redystrybucyjnej działalności państwa ${ }^{51}$. W państwach, które nie są indywidualistyczne, część z funkcji państwa (np. opiekę nad osobami starszymi, ubezpieczenia od chorób i zdarzeń losowych) przejmują wspólnoty, co powoduje wzrost efektywności.

Pozytywny wpływ na innowacyjność. Zwykło uważać się, że to cechy związane z indywidualizmem, np.: chęć wyróżnienia się, wspierają innowacyjność. Jednakże istnieją argumenty świadczące o prawdziwości odwrotnej zależności, czyli to orientacja społeczeństwa na wspólnoty zwiększa poziom innowacyjności52. Robert Hurley ${ }^{53}$ doszukuje się przyczyn tego związku w owocniejszej współpracy i otrzymywanym przez innowatorów wsparciu innych ludzi.

Damien Power i in. ${ }^{54}$, na podstawie analizy inwestycji w rozwijających się krajach Azji oraz gospodarkach wysokouprzemysłowionych, stwierdzaja, że w gospodarkach, gdzie wspólnotowość jest silna, częściej inwestuje się w miękkie czynniki produkcji, tj. kapitał ludzki, zmiany organizacyjne itd. Z drugiej strony, w gospodarkach opartych na indywidualizmie preferowane są inwestycje w aktywa trwałe. Jak można się domyślać, wyższa jakość kapitału ludzkiego sprzyja innowacyjności.

Inną różnicą w sposobie przeprowadzania innowacji jest preferowanie innowacji procesowych w krajach zorientowanych wspólnotowo ${ }^{55}$. Jak wiadomo, wiążą się one z mniejszym ryzykiem niepowodzenia związanego z brakiem popytu. Podsumowując, społeczeństwa indywidualistyczne tworzą efektywne środowisko dla fazy inwencji, natomiast wspólnotowość sprzyja komercjalizacji nowości.

\section{ANALIZA EKONOMETRYCZNA}

W poprzedniej części pokazano, że istnieją mechanizmy przyczynowe, które łączą orientację społeczeństwa na wspólnoty z tempem rozwoju ekonomicznego. Przeprowadzona poniżej analiza ekonometryczna będzie miała za zadanie odpowiedzieć na pytanie, czy badany związek jest na tyle silny, by istotnie determinować różnice w tempie wzrostu gospodarczego pomiędzy krajami.

W celu ograniczenia wpływu innych zmiennych (np. uwarunkowań instytucjonalnych, innych wymiarów kultury itd.) zdecydowano się przeprowadzić analizę na przykładzie krajów należących do Unii Europejskiej. Mogłoby się wydawać, że różnice w poziomie orientacji na indywiduum lub wspólnoty w wybranej grupie krajów są na tyle nieistotne, że nie pozwolą na przeprowadzenie analizy. Rzeczywiście, zróżnicowanie kulturowe jest mniejsze niż - dla przykładu pomiędzy krajami europejskimi a azjatyckimi, lecz wystarczające, by umożliwić wyciagnięcie wniosków na temat badanej zależności przyczynowej. Zróżnicowanie w wymiarze indywidualizm/wspólnotowość pomiędzy krajami Unii Europejskiej wynika z kilku czynników, m. in. sukcesu reformacji. ${ }^{56}$

Do budowy modelu użyto danych makroekonomicznych zaczerpniętych z baz Eurostatu ${ }^{57}$ oraz miary indywidualizmu/wspólnotowości opracowanej przez E. Dienera i in. ${ }^{58}$ na podstawie danych pochodzących z badania World Values Survey (WVS II). Wszystkie zmienne zostały uśrednione dla okresu 2002-2012.

Obliczone współczynniki korelacji pomiędzy poziomem wspólnotowości a wzrostem gospodarczym są istotne statystycznie w obu analizowanych okresach i wskazuja, że orientacja na wspólnoty koreluje z szybszym rozwojem ekono-

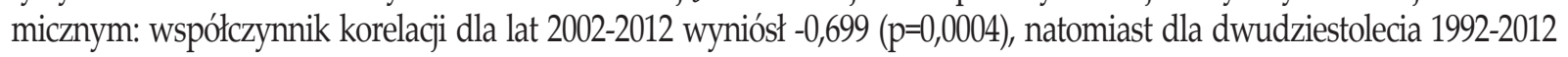
$-0,659$ ( $\mathrm{p}=0,001)$. Uzyskane wyniki potwierdzają wyniki badania ${ }^{59}$ Adama Czerniaka, który wykazał, że państwa zorientowane wspólnotowo są bardziej odporne na kryzysy.

51 R. Ball, Individualism, Collectivism... dz. cyt.

52 N. Rosenbusch i in., Is innovation... dz. cyt.

53 R. Hurley, Group culture and its effect on innovative productivity, ,IJournal of Engineering and Technology Management", 1995, tom 12, s. 57-75.

54 D. Power, T. Schoenherr, D. Samson, The cultural characteristic of individualism/collectivism A comparative study of implications for investment in operations between emerging Asian and industrialized Western countries, "Journal of Operations Management”, 2010, tom 28, nr 3, s. $206-222$.

55 A. Vecchi, L. Brennan, A cultural perspective on innovation in international manufacturing, "Research in International Business and Finance”, 2009, tom 23, nr 2, s. 181-192.

56 A. Buss, The evolution of Western individualism, „Religion”, 2001, tom 573, s. 57-84.

57 Statistics Database, Eurostat, http://epp.eurostat.ec.europa.eu/portal/page/portal/statistics/search_database, 12.04.2014.

58 E. Diener i in., Similarity of the relations between marital status and subjective well-being across cultures, "Journal of Cross Cultural Psychology", tom 31, 2000, str. 419-436. Tabela 1.

59 A. Czerniak, Wptyw wartości wspólnotowych na stabilność ścieżki wzrostu gospodarczego [w:] T. Dołęgowski (red.), Rozzoój gospodarczy a wartości wspólnotowe, Wydawnictwo Szkoły Głównej Handlowej w Warszawie, Warszawa 2012. 
Rysunek 4. Wykresy rozrzutu dla miary indywidualizmu wspólnotowości (IC; im wyższa wartość, tym silniejsza orientacja na indywiduum) oraz wzrostem gospodarczym.
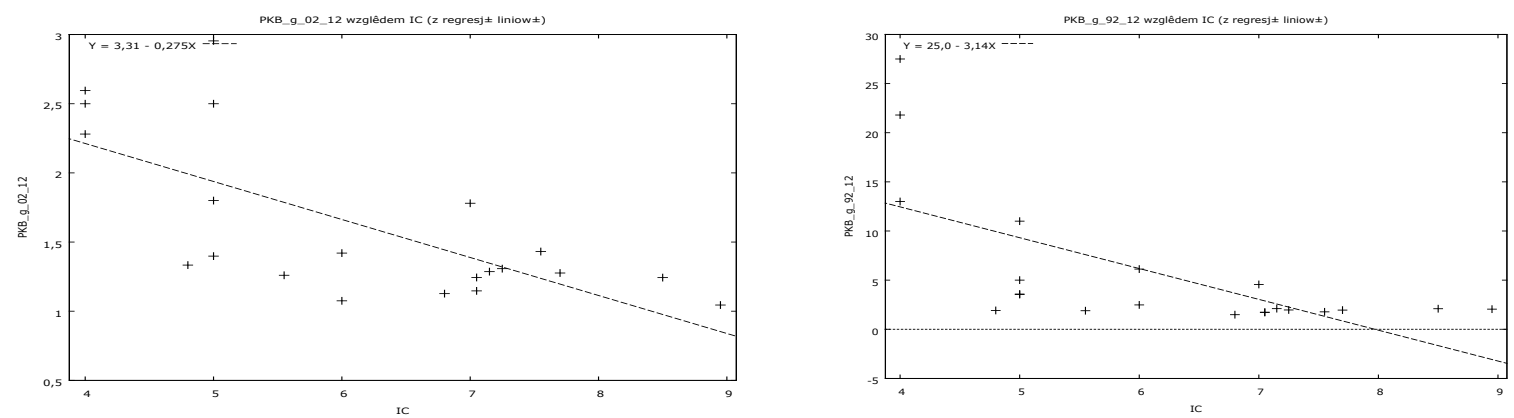

Źródło: opracowanie własne

Aby potwierdzić i uprawomocnić wnioski wyciaggnięte na podstawie zaobserwowanych korelacji, przeprowadzono estymację dwóch modeli. Pierwszy z nich to popularny model wzrostu gospodarczego, stworzony przez Roberta Barro ${ }^{60}$, który uznał za istotne dla wzrostu gospodarczego: poziom edukacji, średnią oczekiwaną długość życia, płodność, poziom konsumpcji rządowej, jakość prawa, inflację, terms-of-trade. W związku z ograniczoną w stosunku do oryginalnego modelu liczbą instancji, ti. krajów branych pod uwagę, jedynie trzy zmienne makroekonomiczne są istotne statystycznie w modelu estymowanym dla 21 krajów Unii Europejkkiej. Zgodnie z Modelem 1, wzrost gospodarczy jest pozytywnie zależny od oczekiwanej długości życia oraz negatywnie od odsetka osób kończących szkołę średnią i procentowej wielkości PKB wydawanej przez rząd.

Model 1. Estymacja KMNK, wykorzystane obserwacje 1-27

Zmienna zależna: PKB_growth_02_12

$\begin{array}{llllll} & \text { Wspótczynnik } & \text { Błąd stand. } & \text { t-Studenta } & \text { wartość } p & \\ \text { schooling } & -0,0220095 & 0,00824702 & -2,6688 & 0,01343 & * * \\ \text { gov_consumption } & -0,0555501 & 0,0203975 & -2,7234 & 0,01185 & * * \\ \text { life_expectancy } & 0,0626773 & 0,0133401 & 4,6984 & 0,00009 & * * *\end{array}$

$\begin{array}{llll}\text { Średn. aryt. zm. zależnej } & 1,611276 & \text { Odch. stand. zm. zależnej } & 0,572907 \\ \text { Suma kwadratów reszt } & 6,826491 & \text { Błąd standardowy reszt } & 0,533326 \\ \text { Wsp. determ. R-kwadrat } & 0,913184 & \text { Skorygowany R-kwadrat } & 0,905949 \\ \text { F(3, 24) } & 84,14862 & \text { Wartość p dla testu F } & 7,08 \mathrm{e}-13 \\ \text { Logarytm wiarygodności } & -19,74849 & \text { Kryt. inform. Akaike'a } & 45,49697 \\ \text { Kryt. bayes. Schwarza } & 49,38449 & \text { Kryt. Hannana-Quinna } & 46,65294\end{array}$

Do uzyskanego powyżej modelu dodano zmienną IC określającą poziom orientacji na indywiduum/wspólnoty. Jeżeli nowe równanie regresji będzie lepiej określać tempo rozwoju ekonomicznego a współczynnik przy nowo dodanej zmiennej niezależnej będzie istotny statystycznie, można wyciągnąć wniosek, że pomiędzy analizowanymi w artykule zmiennymi zachodzi zależność przyczynowa.

Takie działanie ma na celu stwierdzenie, czy nowo dodana zmienna wnosi do modelu dodatkową wartość informacyjna, co jest wymogiem pozwalającym stwierdzić istnienie zależności przyczynowej pomiędzy zmiennymi zgodnie z definicją zaproponowaną przez Norberta Wienera ${ }^{61}$. Nową wersję modelu estymowanego klasyczną metodą najmniejszych kwadratów przedstawia Model 2:

60 R. Barro, Determinants of Economic Growth: A Cross-Country Empirical Study, „,NBER Working Paper”, 1996, nr 5698, s. 178-183.

61 M. Maziarz, A review of the Granger-causality fallacy, "The Journal of Philosophical Economics. Reflections of Economic and Social Issues", 2015, tom VIII nr 2, s. 86-105. 
Model 2. Estymacja KMNK, wykorzystane obserwacje 1-27 ( $\mathrm{n}=21)$

Liczba pominiętych niekompletnych obserwacji: 6

Zmienna zależna: PKB_growth_02_12

\begin{tabular}{|c|c|c|c|c|c|}
\hline & Współczynnik & Btad stand. & t-Studenta & wartość p & \\
\hline IC & $-0,19767$ & 0,0949761 & $-2,0813$ & 0,05284 & * \\
\hline gov_consumption & $-0,0391033$ & 0,0221254 & $-1,7673$ & 0,09511 & * \\
\hline life_expectancy & 0,0666898 & 0,0126215 & 5,2838 & 0,00006 & $* * *$ \\
\hline schooling & $-0,0165835$ & 0,00927101 & $-1,7888$ & 0,09149 & $*$ \\
\hline Średn. aryt. zm. zależnej & & 1,619325 & Odch. stand. zm. zależnej & & 0,583809 \\
\hline Suma kwadratów reszt & & 3,942063 & Błąd standardowy reszt & & 0,481545 \\
\hline Wsp. determ. R-kwadrat & & 0,936298 & Skorygowany R-kwadrat & & 0,925057 \\
\hline $\mathrm{F}(4,17)$ & & 62,46718 & Wartość p dla testu F & & $6,13 e-10$ \\
\hline Logarytm wiarygodności & & $-12,23312$ & Kryt. inform. Akaike’a & & 32,46623 \\
\hline Kryt. bayes. Schwarza & & 36,64432 & Kryt. Hannana-Quinna & & 33,37299 \\
\hline
\end{tabular}

Specyfikacja uzyskanego powyżej modelu jest właściwa. Reszty modelu są homoskedastyczne (test Whitéa nie pozwala odrzucić $\left.\mathrm{H}_{\sigma^{\prime}} \mathrm{p}=0,103\right)$, co oznacza, że nie występuje korelacja pomiędzy zmiennymi a resztami modelu. Świadczy to o właściwej postaci funkcyinej modelu. Rozkład reszt jest normalny (test normalności rozkładu nie pozwala odrzucić $\mathrm{H}_{0}$ $\mathrm{p}=0,32425)$. Porównanie dopasowania obu modeli do danych wskazuje, że zmienne niezależne użyte w Modelu 2 lepiej określają tempo rozwoju ekonomicznego:

Współczynnik determinacji $R^{2}$ ma wyższą wartość (0,936 dla Modelu 2, 0,913 dla Modelu 1).

Wartość kryterium informacyjnego Akaike'a jest niższa (32,37 dla Modelu 2; 49,5 dla Modelu 1).

Przeprowadzona analiza świadczy o tym, że wskaźnik IC istotnie statystycznie determinuje tempo rozwoju ekonomicznego: wzrost poziomu indywidualizmu mierzonego wskaźnikiem IC o jeden punkt powoduje spadek tempa rozwoju ekonomicznego o 1,82 punktu procentowego rocznie, czyli aż o 20\% w okresie dekady.

Następnie, w celu uprawdopodobnienia otrzymanych rezultatów, zastąpiono w Modelu 2 zmienną IC danymi opisującymi wielkość wydatków rządowych na opiekę społeczną per capita, por. Model 3. Zgodnie powyższymi rozważaniami, wielkość wydatków rządowych na opiekę społeczną jest negatywnie skorelowana z poziomem wspólnotowości w społeczeństwie.

Model 3. Estymacja KMNK, wykorzystane obserwacje 1-21

Zmienna zależna: PKB_growth_02_12

\begin{tabular}{|c|c|c|c|c|c|}
\hline & Wspótczynnik & Btad stand. & $t$-Studenta & wartość $p$ & \\
\hline schooling & $-0,0207941$ & 0,00670699 & $-3,1004$ & 0,00650 & $* * *$ \\
\hline government_consumption & $-0,0570442$ & 0,0176933 & $-3,2240$ & 0,00498 & $* * *$ \\
\hline life_expectancy & 0,0679185 & 0,0118951 & 5,7098 & 0,00003 & $* * *$ \\
\hline expenditure_on & $-6,41021 e-05$ & 3,11139e-05 & $-2,0602$ & 0,05502 & $*$ \\
\hline Średn. aryt. zm. zależnej & 1,555494 & \multicolumn{2}{|c|}{ Odch. stand. zm. zależnej } & & 0,492208 \\
\hline Suma kwadratów reszt & 2,748714 & \multicolumn{2}{|c|}{ Błąd standardowy reszt } & & 0,402106 \\
\hline Wsp. determ. R-kwadrat & 0,950613 & \multicolumn{2}{|c|}{ Skorygowany R-kwadrat } & & 0,941897 \\
\hline $\mathrm{F}(4,17)$ & 81,80433 & \multicolumn{2}{|c|}{ Wartość p dla testu F } & & $7,14 \mathrm{e}-11$ \\
\hline Logarytm wiarygodności & $-8,447123$ & \multicolumn{2}{|c|}{ Kryt. inform. Akaike'a } & & 24,89425 \\
\hline Kryt. bayes. Schwarza & 29,07234 & \multicolumn{2}{|c|}{ Kryt. Hannana-Quinna } & & 25,80100 \\
\hline
\end{tabular}

Powyższy model charakteryzuje się istotnością statystyczną oszacowanych parametrów regresji. Ponadto, wartości współczynnika determinacji $R^{2}(0,95$ w porównaniu do 0,91) i kryterium informacyjnego Aikaike’a ( 24,9 w porównaniu do 49,5) świadczą o lepszym dopasowaniu do danych. Podobnie jak w przypadku Modelu 2, wynik testu White'a $(\mathrm{p}=, 013)$ i normalności rozkładu reszt ( $\mathrm{p}=0,71)$ wskazują na poprawną specyfikację. 
Przeprowadzona analiza ekonometryczna pozwala stwierdzić, że istnieje statystycznie istotna zależność przyczynowa, zgodnie z którą wyższy poziom wspólnotowości (bez względu na sposób wyrażenia) sprzyja szybszemu rozwojowi ekonomicznemu.

\section{ZAKOŃCZENIE}

Celem artykułu było przedstawienie odpowiedzi na pytanie, czy orientacja społeczeństwa na wspólnoty (a nie indywiduum) jest przyczyną szybszego rozwoju ekonomicznego. Przedstawiona argumentacja może świadczyć o istnieniu relacji przyczyna - skutek pomiędzy analizowanymi zmiennymi. Wyższy poziom wspólnotowości nie tylko jest pozytywnie skorelowany z wyższym tempem wzrostu gospodarczego istnieją także mechanizmy łączące ten wymiar kultury z ekonomia.

Uzyskane wyniki mają nie tylko charakter poznawczy. Poziom wspólnotowości mierzony wskaźnikiem IC jest wyższy w krajach o wyższym poziomie PKB per capita, (por. Tabela 3), co przemawia za prawdziwością teorii modernizacji (ang:: modernisation theory), która głosi, iż wraz ze wzrostem dobrobytu rośnie poziom indywidualizmu społeczeństw ${ }^{62}$. Jeżeli w toku dalszych badań uda się stwierdzić, że powyższa zależność ma charakter przyczynowy, opisane w niniejszym artykule wyniki badań będą mogły zostać wykorzystane do kreowania takiego otoczenia kulturowego, które jest korzystniejsze z punktu widzenia gospodarki, tj. kultury zorientowanej wspólnotowo.

\section{Bibliografia:}

[1] Ball R., Individualism, Collectivism, and Economic Development, „The Annals of the American Academy of Political and Social Science”, 2001, tom 573

[2] Barro R., Determinants of Economic Growth: A Cross-Country Empirical Study, „NBER Working Paper”, 1996, nr 5698

[3] Buss A., The evolution of Western individualism, „Religion”, 2000, nr 30

[4] Case A., Katz L., The Company You Keep: The Effects of Family and Neighborhood on Disadvantaged Youths, „NBER Working Paper”, nr 3705

[5] Chen F., West S., Measuring individualism and collectivism: The importance of considering differential components, reference groups, and measurement invariance ,"Journal of Research in Personality", 2008, tom 42

[6] Cobb S., Social support as a moderator of life stress „Psychomatic Medicine”, 1976, tom 38

[7] Coleman J., Social Capital in the Creation of Human Capital [w:] Foundations of Social Theory, Harvard University Press, Cambridge 1990, str. 95-120.

[8] Czerniak A., Wpływ wartości wspólnotowych na stabilność ścieżki wzrostu gospodarczego [w:] T. Dołęgowski i in., Rozwój gospodarczy a wartości wspólnotowe, Warszawa 2012

[9] Diener E. i in., Similarity of the relations between marital status and subjective well-being across cultures, „Journal of Cross Cultural Psychology", 2000, tom 31

[10] Dołęgowski T., Rozwój gospodarczy a wartości wspólnotowe. Między konkurencyjnością a solidarnością [w:] Dołęgowski T. i in., Rozwój gospodarczy a wartości wspólnotowe, Warszawa 2012

[11] Gomez-Mejia L., Wellbourne T., Compensation strategies in a global context „Human Resource Planning", 1991, tom 14

[12] Green E. i in., Variation of Individualism and Collectivism within and between 20 Countries: A Typological Analysis, "Journal of Cross-Cultural Psychology", 2005, tom 36, nr 3

[13] Gwartney J.i in., Economic Freedom, Institutional Quality and Cross-Cuontry Differences in Income and Growth, "Gato Journal”, 2002, tom 24, nr 3

[14] Hamamura T., Cultures Becoming Individualistic?, „A Cross-Temporal Comparison of Individualism-Collectivism in the United States and Japan", 2012, tom 16, nr 1

[15] Hofstede G., Culture's consequences, Beverly Hills, 1980

[16] Hofstede G., Empirical models of cultural differences, [w:] Bleichrodt N., Drenth P. (red), Contemporary issues in cross-cultural psychology, Lisse, 1991

[17] Huff L., Kelley L., Is collectivism a liability? The impact of culture on organizational trust and customer orientation: a seven-nation study, „Journal of Business Research", 2005, tom 58

[18] Hurley R. Group culture and its effect on innovative productivity, ,Journal of Engineering and Technology Management", 1995, tom 12

[19] Johnson J., Lenartowicz T., Culture, Freedom and Economic Growth: Do Cultural Values Explain Economic Growth?, "Journal of World Business", 1998, tom 34, nr 4

[20] Ketkar S., Kock N., Parente R., Verville J., The impact of individualism on buyer-supplier relationship norms, trust and market performance: An analysis of data from Brazil and the USA, „International Business Review", 2012, tom 21

[21] Knack S., Keefer Ph., Does Social Capital Have an Economic Payoff?, „The Quarterly Journal of Economics”, 1997, tom 112, nr 4

[22] Lewis-Beck M. (red.), The SAGE Encyclopedia of Social Science Research Methods, 2003

[23] Little D., Varieties Of Social Explanation: An Introduction To The Philosophy Of Social Scinece, Westview Press, 1991

[24] Maziarz M., A review of the Granger-causality fallacy, "The Journal of Philosophical Economics. Reflections of Economic and Social Issues", 2015, tom VIII, nr 2, 2015, s. 2-21

62 T. Hamamura, Cultures Becoming Individualistic?, „A Cross-Temporal Comparison of Individualism-Collectivism in the United States and Japan", tom 16, nr 1, 2012, s. 3-24. 
[25] Maziarz M., Spór o obiektywne istnienie obiektów teorii ekonomicznych. Argument na rzecz esencjalizmu, "Przegląd Prawniczy, Ekonomiczny i Społeczny", 2013, nr 4

[26] McClelland D., The Achieving Society, New York, 1976

[27] Milne A., Kubuś Puchatek, 1988

[28] Naroll R., The moral order, Beverly Hills 1983

[29] Parkes L. i in., Person-organization fit across cultures: an empirical investigation of individualism and collectivism, „Applied Psychology: And International Review", tom 50, nr 1, 2001

[30] Peterson R., Enterpreneurship and organization, [w:] Nystorm P. i Starbuck W., (red.) Handbook of Organizational Design, tom 1, Oxford, 1980

[31] Power i in., The cultural characteristic of individualism/collectivism: A comparative study implications for investment in operations between emerging Asian and industrialized Western cuntries, ,JJournal of Operations Management", 2010, nr 28

[32] Putnam R., Making Democracy Work: Civic Traditions in Modern Italy, Princeton, 1993

[33] Putnam R., The Prosperous Community: Social Capital and Public Life [w:] Blair K., Murphy R., Almjeld J., (red.), Cross Currents: Culteres, Communities, Technologies, Cengage Learning, 2013

[34] Ramamoorthy N. i in., Individualism-collectivism orientation and employee attitudes: A comparison of employees from the high-technology sector in India and Ireland, ",Journal of International Management", 2007, tom 13

[35] Rosenbusch N., Brickmann J., Bausch A., Is innovation always beneficial? A meta -analysis of the relationship between innovation and SMEs, ,IJournal of Business Venturing", tom 26, 2011

[36] Siewierski J., Autonomia jednostki a wspólnota. Analiza Porównawcza rozwoju gospodarczego na Zachodzie i w Azji Wschodniej, Dołęgowski T. i in., Wartości wspólnotowe a rozwój gospodarczy, Warszawa, 2012

[37] Solow R., A contribution to the Theory of Economic Growth, "Quartelry Journal of Economics, 1956, tom 70, nr 1

[38] Taylor M., Wilson S., Does culture still matter?: The effects of individualism on national innovation rates, , Journal of Business Venturing", 2012, tom 27,2012

[39] Tiessen J., Individualism, Collectivism and Enterpreneurship: a Framework for International Comparative Research, „Journal of Business Venturing, 1997 , tom 12

[40] Triandis H., Hui C., Individualism-Collectivism. A Study of Cross-Cultural Researchers, „Journal of Cross-Cultural Psychology", 1986, tom 17, nr 2

[41] Vecchi A., Brennan L., A cultural perspective on innovation in international manufacturing, „Research in International Business and Finance”, 2009 , tom 23, nr 2

[42] Wagner J., Studies of Individualism-Collectivism: Effects on Cooperation in Groups, „Academy of Management Journal, 1995, tom 38

[43] Weber M., The objectivity of the Sociological and Social-Political Knowledge, The Essential Weber: A Reader, Psychology Press, 1904

[44] Zak P., Knack S., Trust and Growth, „The Economic Journal”, tom 111, wydanie 470, 2001

\section{Netografia:}

[45] Smith A., An Inquiry into the Nature and Causes of the Wealth of nations, Soares S. M. (red.), MetaLibri, 2007, http://metalibri.wikidot.com/title:aninquiry-into-the-nature-and-causes-of-the-wealth-of; 11.04.2014 